\title{
BRINCADEIRAS ATEMPORAIS COMO CONHECIMENTO NAS AULAS DE EDUCAÇÃO FÍSICA
}

\section{ENCUENTROS ATEMPORAIS COMO CONOCIMIENTO EN LAS CLASES DE EDUCACIÓN FÍSICA}

\author{
Taina Pereira ${ }^{1}$; \\ Vanessa da Silva da Silveira²; \\ Viviane Ribeiro Pereira ${ }^{3}$; \\ Vânia Vitório ${ }^{4}$
}

\begin{abstract}
Resumo: O presente artigo tem como objetivo explicitar experiências no PIBID (Programa Institucional de Bolsas de Iniciação à Docência) subprojeto de Educação Física UNESC,com brincadeiras atemporais em turmas do $1^{\circ}$ e $2^{\circ}$ ciclo, no município de Criciúma SC, em que os princípios da obra Coletivo de Autores (1992) se materializem em aula.Foi produzido a partir do relatório final do ano, em que se desenvolveu e se refletiu acerca das práticas pedagógicas realizadas no decorrer do ano letivo de 2016. Mediante a isso, constatou-se que as práticas pedagógicas foram de grande significado, pois o objetivo do planejamento foi contemplado, visto que houve a apropriação doconhecimento abordadoconstatada na avaliação final do conteúdocom os educandos.Diante do exposto, também pensamos ser valido explicitar que tais atuações foi de grande contribuição na formação das acadêmicas.
\end{abstract}

Palavras chaves: PIBID; Brincadeiras atemporais; Formação; Educação Física.

Resumen: El presente artículo tiene como objetivo explicitar experienciasenel PIBID (Programa Institucional de Becas de Iniciación a laDocencia) subproyecto de Educación Física - UNESC, con bromas atemporalesen grupos del $1^{\circ}$ y $2^{\circ}$ ciclo, enelmunicipio de Criciúma - SC, en que losprincipios de laobra Colectiva de Autores (1992) se materializanenclase. Se produjo a partir del informe final delaño, enel que se desarrolló y se reflejó acerca de lasprácticas pedagógicas realizadas enel curso delaño escolar de 2016. Mediante ello, se constató que lasprácticas pedagógicas fueron de gran significado, puesel objetivo delplanificaciónfue contemplada, ya que hubolaapropiacióndelconocimiento abordado constatada enlaevaluación final delcontenidoconlos educandos. Ante loexpuesto, también pensamos que es valido explicitar que tales actuacionesfueron de grancontribuciónenlaformación de las académicas.

1 UNESC - Universidade do Extremo Sul Catarinense (tainapereira003@hotmail.com)

2 UNESC - Universidade do Extremo Sul Catarinense (vanessa.renan_@hotmail.com)

3 UNESC - Universidade do Extremo Sul Catarinense (vivianeribeirop@hotmail.com)

4 UNESC - Universidade do Extremo Sul Catarinense (vvi@unesc.net)

Criar Educação, Criciúma, v. 6, n², julho/novembro 2017.- PPGE - UNESC 
Palabras clave:PIBID; Bromas atemporales; Formación; Educación Física.

\section{INTRODUÇÃO}

O presente artigo é um relato de experiência vivenciada no Programa Institucional de Bolsa de Iniciação à Docência - PIBID, subprojeto de Educação Física na Universidade do Extremo Sul Catarinense - UNESC. Sendo que tal projeto tem como objetivo: Contribuir para a qualidade da formação inicial de professores nos cursos de licenciatura, relacionando a educação superior e educação básica;inserir os licenciados no cotidiano de escolas da rede pública de educação, ea articulação ${ }^{5}$ entre teoria e prática necessárias à formação dos docentes (CAPES,2008).

O artigo se constituiu a partir do relatório realizado ao final do ano de 2016, em que se desenvolveu e refletiu acerca das práticas pedagógicas realizadas no decorrer do ano letivo.As atuações foram realizadas com brincadeiras atemporais em turmas do $1^{\circ}$ e $2^{\circ}$ ciclo, no município de Criciúma - SC, em que os princípios de seleção e sistematização do conhecimento da obra do Coletivo de Autores (1992) se materializaramem aula.Todas as atuações foram supervisionadas pela professora supervisora na escola.

O PIBID - subárea Educação Física - da instituição Universidade do Extremo Sul Catarinense - UNESC se desenvolve em encontros quinzenais na instituição, a fim de efetivar debates e estudos sobre questões pedagógicas, bem como para a organização e controle das atividades a serem realizadas nas escolas, sendo que o desenvolvimento do programa na escola era semanal.

$\mathrm{Na}$ escola em que se desenvolviam as atuações, a professora supervisora tinha oito bolsistas, sendo que este se subdividia em dois grupos de quatro integrantes, que atuavam em dias distintos da semana. Sendo que um grupo de acadêmicos atuava na segunda-feira, e o outro na sexta-feira, contemplando assim as aulas semanais. Assim, ambos os grupos atuavam nas mesmas turmas, sendo o

\footnotetext{
5 Vale ressaltar que esta concepção de articulação de teoria e prática é apontada pelos documentos da CAPES, sendo que as pesquisadoras compreendem que teoria e prática se dão em unidade, e não de forma fragmentada. Como nos aponta Leóntiev (1978), a atividade interna e externa são uma unidade, e não uma superior a outra.
}

Criar Educação, Criciúma, v. 6, n², julho/novembro 2017.- PPGE - UNESC 
$4^{\circ}$ e $5^{\circ}$ ano matutino. Dessa forma, o planejamento foi desenvolvido com o grupo todo de pibidianos, para possibilitar a continuidade do conteúdo.

Para uma organização metodológica e didática, o subprojeto da Educação Física utiliza-se da proposta didático-metodológica Critico-Superadora, apresentada no livro Metodologia do Ensino da Educação Física, obra de 1992, também conhecida por Coletivo de Autores.

Vale deixar explícito a razão de se tomar como base tal proposta didáticometodológica. Isto se deu pelo fato de que a proposta do Estado de Santa Catarina e a proposta do Município são pautadas na perspectiva Histórico-Cultural. Sendo assim, a referida obra, Metodologia do Ensino da Educação Física, tem como um de seus pressupostos teóricos a teoria Histórico-Cultural.

Mediante a isso, os planejamentos foram desenvolvidos de acordo com a perspectiva acima citada. Neste sentido, o princípio de seleção do conteúdo utilizado para a determinação dos conteúdos, foi à relevância social que o mesmo tinha para a escola, uma vez que estavam trabalhando com projeto folclórico, tratando assim do conteúdo brincadeiras atemporais nas aulas de Educação Física.

A proposta Crítico-Superadora expõe princípios curriculares no trato do conhecimento, em que estes organizam e sistematizam os conteúdos da Educação Física com a finalidade de possibilitar uma melhor compreensão do mesmo pelos alunos. Sendo que o jogo, a dança, o esporte, a ginástica, a capoeira, a arte circense, a luta, entre outros, são os objetos de estudo da Educação Física, sendo estes denominados por Cultura Corporal(COLETIVO DE AUTORES, 1992).

Esta perspectiva crítica da Educação Física aponta que a sociedadese encontra dividida em duas classes antagônicas, sendo a Classe Trabalhadora e a Classe Proprietária. Com isso, a primeira tem como interesse apenas a sobrevivência, e para isso vende sua força de trabalho por um mínimo salário, e a segunda classe tem como interesse manter seu status quo,visando ampliar seus patrimônios e riquezas, não perspectivando uma mudança na sociedade, ou seja, a superação de classes (COLETIVO DE AUTORES, 1992).

Neste sentido, Ponce (1986) aponta como tal sociedade dividida em classes refletiu, e sabe-se que ainda reflete, sobre a educação de ambas as classes. Com isso, a educação pública serviu para que a ideologia dominante permanecesse 
em vigor sobre a classe trabalhadora, mantendo assim as desigualdades sociais, ao invés de combatê-la. "Essa diferença social é própria do sistema econômico em que vivemos, o capitalismo. O capitalismo coloca em situações diferentes os que detêm o capital e os que trabalham para produzi-los" (KRUPPA, 1994, p. 47).

Desse modo, abaixo apontaremos as especificidades da proposta pedagógica apresentada por Coletivo de Autores (1992).

Tal proposta expõe uma visão de currículo que esteja de acordo com os interesses da classe trabalhadora, sendo este um currículo ampliado, visa dar contade uma educação crítica, em que por meio do conhecimento científico, o aluno possa se apropriar dos conhecimentos historicamente construídos, e assim perceba a realidade de uma forma crítica, contribuindo na modificação da sociedade, de acordo com o interesse de sua classe (COLETIVO DE AUTORES, 1992). Neste sentido, Silvano e Ortigara (2016, p.465) alegam que;

O currículo no contexto escolar é uma dinâmica que possibilita intervenções em suas contradições, ideologias, posicionamentos no processo de aprendizagem. Nessa dinâmica, estão disciplinas, tempos, espaços, gestão, formação docente e intervenções da comunidade escolar.

No currículo ampliado, têm-se alguns princípios para o trato com o conhecimento. Sendo estes divididos em critérios para a Seleção do Conteúdo: Relevância Social do Conteúdo; Adequação ás Possibilidades Sócio-cognocitivas; e a Contemporaneidade do Conteúdo. E critérios para a Sistematização eOrganizaçãodoConhecimento: Confronto e Contraposição dos Saberes; Simultaneidade dos Conteúdos Enquanto Dados da Realidade; Espiralidade da Incorporação das referências do pensamento; e a Provisoriedade do Conhecimento.

A obra apresenta uma ideia deciclos de escolarização, ao invés de seriação, apontando que "Ao introduzir o modelo dos ciclos, sem abandonar a referência às séries, busca-se construir pouco a pouco as condições para que o atual sistema de seriação seja totalmente superado" (COLETIVO DE AUTORES, 1992,p.34-35). Diferentemente da realidade da escola em que houve as atuações, em que as turmas são organizadas por seriação.

Com isso, expõe quatro ciclos: o primeiro é o ciclo de organização da identificação dos dados da realidade que corresponde desde a educação infantil até a $3^{\mathrm{a}}$ série $\left(1^{\circ}\right.$ ao $4^{\circ}$ ano). Neste ciclo o educando está organizando seus 
pensamentos e críticas sobre o mundo que vive, entretanto ainda com uma visão muito sincrética.

O segundo é o ciclo de iniciação à sistematização do conhecimento, que vai da $4^{\mathrm{a}}$ à $6^{\mathrm{a}}$ serie $\left(5^{\circ}\right.$ ao $7^{\circ}$ ano), em que o aluno começa a ampliar seus conhecimentos já adquiridos no ciclo anterior, tomando consciência da atividade teórica e fazendo uma leitura da realidade.

O terceiro ciclo correspondente da $7^{\mathrm{a}}$ à $8^{\mathrm{a}}$ serie $\left(8^{\circ}\right.$ e $9^{\circ}$ ano), é o ciclo que realiza a ampliação da sistematização do conhecimento. Neste sentido, o aluno depois de organizar e iniciar seus conhecimentos começa a ampliar, ou seja, ele toma consciência "[...] de que uma operação mental exige a reconstituição dessa mesma operação na sua imaginação para atingir a expressão discursiva, leitura teórica da realidade" (COLETIVO DE AUTORES, 1992, p. 35).

E o quarto ciclo de aprofundamento da sistematização do conhecimento, sendo do $1^{a}, 2^{a}$, e $3^{a}$ ano do ensino médio, em que é o momento de pesquisa e reflexão mais detalhada sobre o objeto de estudo.

A obra traz também um capítulo direcionado à avaliação escolar, em que aponta para uma avaliação voltada para a criticidade, para que esta não sirva apenas para mensurações com fins classificatórios e seletivos.

Com isso, alega ser necessário que o professor saiba que cada aluno tem suas individualidades, e que por conta disso, tem um tempo pedagogicamente necessário para a aprendizagem. Com isso, a avaliação não deve servir apenas para avaliar a aprendizagem dos educandos, mas o ensino também, pois a forma como o professor ensina o conteúdo, suas metodologias e o tempo pedagogicamente necessário são fatores de grande peso na hora da avaliação.

[...] o sentido da avaliação do processo ensino-aprendizagem em Educação Física é o de fazer com que ela sirva de referência para análise da aproximação ou distanciamento do eixo curricular que norteia o projeto pedagógico da escola (COLETIVO DE AUTORES, 1992, p. 103).

Com esta breve explanação da proposta didático-metodológica CriticoSuperadora, a seguir apresenta-se os procedimentos metodológicos desta experiência no PIBID, bem como apontaremos alguns momentos em que os princípios curriculares, apontados acima, se materializaram nas aulas de Educação Física realizadas.

Criar Educação, Criciúma, v. 6, n², julho/novembro 2017.- PPGE - UNESC 


\section{PROCEDIMENTOS METODOLÓGICOS}

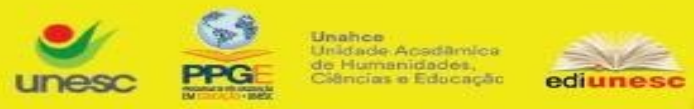

Este relato de experiência se deu a partir do desenvolvimento do programa do PIBID, numa escola municipal de Criciúma - SC, no ano de 2016.

Nesse sentido, durante $o$ ano letivo as acadêmicas estiveram presentes na escola realizando primeiramente uma análise de conjuntura, em que posteriormente mediante a análise realizada, se elaborou o planejamento com o grupo de bolsistas juntamente com a professora supervisora, logo em seguida foram realizadas as atuações de acordo com o devido planejamento.

Como mencionado acima, primeiramente todos os bolsistas se concentraram emrealizar uma análise de conjuntura, uma vez queSouza (1984, p.08) alega que a análise de conjuntura é um ato totalmente político e difícil de ser efetivado, pois carece muita competência para envolver todos os elementos abrangidos na situação específica "[...] exige também um tipo de capacidade de perceber, compreender, descobrir sentidos, relações, tendências a partir dos dados e das informações".

A instituição escolar é muito organizada, contando com uma gestão que propiciou total apoio as acadêmicas, não se opondo em momento algum a presença destas na escola e nem a proposta de ensino.Aescola fica localizada num bairro de vulnerabilidade social, em que as famílias moram em residências de condições precárias, muitas vezes sem saneamento básico e rede de esgoto.

O planejamento foi realizado de acordo com a relevância social que havia para a escola, perante o projeto folclórico que a mesma estava idealizando. Dentro disso, foram escolhidas algumas brincadeiras atemporais:bolinha de gude, perna de pau, cinco marias e o pião, apoiadas na decisão de todos os envolvidos, sendo eles os bolsistas e a professora supervisora. Tinha-se como objetivo geral do conteúdo: Conhecer brevemente o histórico das brincadeiras atemporais; e praticar as atividades culturalmente e historicamente conhecidas.

Partindo disso, as atuações foram realizadas pelas acadêmicas em dias pré-determinados e seguindo a sequência do planejamento. Vale ressaltar que não foi possível que todos pibidianos atuassem em todas as quatro brincadeiras, uma vez que havia oito bolsistas atuando sobre o mesmo planejamento, e o mesmo tinha em média quatro a cinco aulas para cada brincadeira. Porém, acompanhamos o 
desenvolvimento do planejamento de todas as aulas, durante as atuações dos outros bolsistas.

\section{RESULTADOS E DISCUSSÕES}

Apresentaremos a seguir as reflexões a respeito da efetivação das atuações desenvolvidas no PIBID, com os princípios de seleção e sistematização do conhecimento apontado por Coletivo de Autores (1992), nas turmas de $4^{\circ}$ e $5^{\circ}$ ano do ensino fundamental.

Relacionando ao objetivo geral do planejamento, foiexplicitado em todas as brincadeiras o desenvolvimento histórico das mesmas, entretanto em cada uma foi abordado e refletido de maneiras diferentes. Nesse sentido, Coletivo de Autores (1992) traz a importância da historicidade em que o conhecimento é tratado de forma a ser retraçado desde sua gênese, possibilitando ao aluno a visão de historicidade, permitindo-Ihe compreender-se enquanto sujeito histórico, capaz de interferir e modificar a realidade.

[...] essa visão de historicidade tem um objetivo: a compreensão de que a produção humana é histórica, inesgotável e provisória. Essa compreensão deve instigar o aluno a assumir a postura de produtor de outras atividades corporais que, no decorrer da história, poderão ser institucionalizadas (COLETIVO DE AUTORES, 1992, p. 40).

Com isso, para atingir o segundo objetivo, tiveram momentos em que foram manipuladas e praticadas as técnicas de cada brincadeira. Neste sentido,as técnicas devem ser compreendidas como instrumentos necessários de um jogo, porém, entendendo que durante a execução, o que deve prevalecer na consciência do executante é o resultado que essas técnicas têm para o sucesso do jogo (COLETIVOS DE AUTORES, 1992).

Partindo disso, para melhor compreensão será apresentado às reflexões das atuações específicas de cada brincadeira, em que se materializaram os princípios curriculares do trato com o conhecimento. Vale ressaltar que serão apresentados alguns momentos das aulas de maior relevância, que seja possível verificar os princípios se materializando. Entretanto,ocorreram muitos outros momentos em queos princípios também se efetivaram.

Bolinha de gude:ao explanarmos sobre tal conteúdo, demos início fazendo uma apresentação de sua história desde a sua gênese, por meio de uma 
explanação oratória, apresentando-Ihes o conhecimento científico. Neste momento pode-se perceber o princípio curricular de confronto e contraposição de saberes, apontada por Coletivo de Autores (1992). Isso porque os alunos puderam confrontar o senso comum que eles já traziam perante sua pratica social, ou seja, o conhecimento empírico, com o conhecimento científico agora apresentado a eles pelos acadêmicos.

No mesmo conteúdo, houve em determinado dia que o princípio de adequação as possibilidades sócio-cognocitivas foi de certa forma materializado, sendo o dia em que se tinha como planejamento executar a aula em um espaço aberto da escola, mas por conta de condições climáticas o mesmo teve de ser realizado em um espaço coberto da escola. Sendo houve a necessidade de se repensar a dinâmica da aula, para que fosse possível ainda a apropriação daquele conhecimento para os alunos.No entanto, esse princípio abrange ainda, mas do que este pequeno momento da aula.

Com isso, Coletivo de Autores (1992, p.31) aponta que "há de ser ter, no momento da seleção, competência para adequar o conteúdo à capacidade cognitiva e à prática social do aluno, ao seu próprio conhecimento e às suas possibilidades enquanto sujeito histórico".

Após todo o processo de instrumentalização dos alunos, nas últimas linhas de ação deste conteúdo, podemos perceber o avanço que os educandos obtiveram em relação à brincadeira da bolinha de gude, uma vez que muitos alunos nunca haviamjogado tal jogo, e que a partir das aulas começaram a conseguir jogar de forma efetiva, ou seja, com êxito na prática.

No entanto, foi necessária a automatização do conhecimento, para que tal habilidade com o jogo fosse possível, uma vez que para que o aluno possa ter liberdade de criação, e possa realmente se beneficiar de tal conteúdo é necessário que primeiramente tenha dominado o mesmo (SAVIANI, 1992). Por conta disso, as acadêmicas propuseram atividades que justamente tinham como objetivo melhorar a prática social da bolinha de gude, mais especificamente seu lançamento, ou seja, a empunhadura, para que em um próximo momento de contato tivessem maior liberdade para desenvolver de acordo com seus interesses. Havendo neste sentido 
também o princípio de Espiralidade da Incorporação das referências do pensamento, pois os alunos foram se apropriando de maneira espiralada do conhecimento.

O conteúdo da perna de pauteve seu desenvolvimento histórico explanado através de uma brincadeira ${ }^{6}$ realizada no pátio da escola, objetivando uma maneira diferenciada de explanação e com maior dinâmica, buscando dar um sentido e significado a mesma. Assim, despertando um interesse maior sobre a história do conteúdo, sendo que através da mesma é possível fazer com que os alunos compreendam o conhecimento historicamente acumulado e o seu próprio papel de sujeito nessa história (COLETIVO DE AUTORES, 1992).

Com o decorrer das aulas, os alunos foram aprendendo algumas técnicas da perna de pau, assim como na bolinha de gude, como, por exemplo, a subida na mesma. No entanto, foi necessária adequar algumas regras das formas de subir na perna de pau para que pudessem a princípio andar sobre as mesmas. Logo após estas adequações, os próprios alunos começaram a conseguir subir sozinhos, da maneira que melhor thes convinha.Com isso, percebeu-se o princípio da provisoriedade do conhecimentoapontada por Coletivo de Autores (1992), uma vez que os mesmos perceberam que tais adequações eram necessárias naquele momento, até que conseguissem se apropriar da técnica de subida e empunhadura da perna de pau.

Após esta apresentação de como subir na perna de pau, fomos todos para um gramado da escola realizar um circuito com atividade utilizando as pernas de pau, sendo que os alunos foram divididos em grupos, pois havia apenas 05 jogos de perna de pau. Neste momento da aula foi realizada a segunda fase da aula que Coletivo de Autores (1992) aponta, ou seja, o momento em que ocorre a apreensão do conhecimento dos alunos na referida fase.

Assim como nas outras brincadeiras, exceto a perna de pau, o jogo das cinco mariasteve a sua história contada desde a gênese a partir de explicação oral em sala.Logo após isso, no decorrer das linhas de ações foi realizado as apresentações das diversas maneiras que se podejogar a brincadeira, principalmente com o uso de uma e as duas mãos. Com isso buscou-se que todos

$6 \mathrm{~A}$ brincadeira se constituía em um caça a pista, uma vez que os educandos em equipes tinham que encontrar as pistas da história da bolinha de gude e logo compartilhar com o grande grupo.

Criar Educação, Criciúma, v. 6, n², julho/novembro 2017.- PPGE - UNESC 
os educandos experimentassem e conhecesse,mas diversas maneiras constituídas historicamente pela humanidade.

Procurávamos sempre estar frisando aos alunos que aquelas maneiras apresentadas a eles por nós, eram apenas algumas das várias formas existentes construídas historicamente pela humanidade, ou seja, mostrando a elesque o conhecimento é provisório, logo rompendo com a ideia de terminalidade de um conhecimento. Com isso Coletivo de Autores (1992, p. 33) reflete que "[...] a produção humana, seja ela intelectual, cientifica, ética, moral, afetiva etc., expressa um determinado estágio da humanidade e que não foi assim em outros momentos históricos".

Como mencionado acima, foi necessário no decorrer das aulas o ensino das técnicas e manejo das cinco marias, sendo este um dos objetivos gerais das aulas. Neste sentido, Coletivo de Autores (1992, p.41) afirma em relação aos princípios de sistematização do conhecimentoque "esta forma de organizar o conhecimento não desconsidera a necessidade do domínio dos elementos técnicos e táticos, todavia não os coloca como exclusivos e únicos conteúdos da aprendizagem". Isso porque muitas vezes se alega, por falta de conhecimento, que o ensino crítico da Educação Física não deve abordar o ensino das técnicas, pois permearia para uma proposta de ensino tecnicista. No entanto é necessário compreender que a técnica é necessária ao jogo,devendo ser tomada como recurso para apreensão do conhecimento pretendido.

$\mathrm{Na}$ última linha de ação das cinco marias, após os educandos terem experimentadoe conhecidoàs diversas maneiras de manejo, os mesmos foram desafiados a reinventarem outras maneiras de jogar, logo, todos criaram formas bastante diferentes e criativas de jogar. No entanto, é importante deixar claro que de acordo com Saviani (1985) para o aluno criar algo ele deve primeiramente ter o conhecimento, para após transformá-lo.

Após todos criarem suas formas diferentes de jogo com o nome por eles escolhidos, todos formaram um grande círculo para que apresentassem aos demais colegas sua criação. Neste momento da apresentação, houve uma jogada que parecida com o movimento da cesta no basquete,e com isso a acadêmica que estava realizando a atuação articulou a simultaneidade dos conteúdos, perguntando- 
Ihes com o que se parecia aquele movimento, que para a acadêmica seria o lançamento da bola de basquete,buscando fazer a relação de um dos conteúdos da cultura corporal, o basquete, com o jogo das cinco marias. Resultando em diferentes maneiras de se manusear as marias, e além disso, ampliando a sua forma de percepção sobre os jogos, compreendendo que ele pode transformar, a partir de um conhecimento, aquilo que está no jogo.

Sendo assim, tais reflexões que tivemos na sala, possui por finalidade levar o aluno a uma atividade de estudo, uma vez que o mesmo se apropria de um determinado conhecimento para assim transformar a realidade. De acordo com Libâneo; Freitas (2013, p.342) “[...] a aprendizagem escolar é o processo interno de apreensão teórica de um conhecimento mediante a transformação do objeto de conhecimento e, consequentemente, do aluno".

A brincadeira do pião foi para as acadêmicas um pouco difícilde lecionar, uma vez que as mesmas não tinham a prática social do mesmo. Porém, assim como nas outras brincadeiras foi uma grande aprendizagem e um novo conhecimento adquirido.

A brincadeira do pião, por uma questão histórica, acabou sendo muito mais apropriada pelos meninos do que pelas meninas, sendo muitas vezes taxada como "brincadeira de menino". Por conta disso, as meninas das turmas acabaram tendo maior dificuldade na apropriação das técnicas de jogo, o que acabou levando a um avanço menor que os meninos em relação às diferentes formas de se jogar o pião. $O$ que reflete o processo histórico pelas gerações tanto das crianças quanto das acadêmicas em relação a divisão de gêneros nas relações sociais.

Neste sentido, em uma das aulas de tal conteúdo aconteceu uma situação em que não esperávamos.Dois alunos acabaram entrando em discussão por conta de uma disputa que haviam realizado na brincadeira. Com isso a acadêmica que estava atuando neste dia, buscou fazer com que a turma refletisse qual o significado de eles irem para a escola, obtendo como resposta dos mesmos a aprendizagem. A partir disso,questionou que como o colega poderia aprender se não tivesse o pião para praticar?Explicando ainda que quanto mais se pratica mais se tem a habilidade para jogar, e que se o colega perdesse o pião na disputa não teria 
a chance de se apropriar mais das técnicas de jogo, e assim conseguiria aprender mais ou ao nível de quem sabe jogar com maior facilidade.

Neste sentido, Coletivo de Autores (1992, p.66) menciona a necessidade de discutir o quanto alguns jogos são discriminatórios, sendo que;

\begin{abstract}
Dessa forma, os alunos poderão perceber, por exemplo, que um jogo como a "queimada" é discriminatório, uma vez que os mais fracos são eliminados (queimados) mais rapidamente, perdendo a chance de jogar. Isso não significa não jogar "queimada", senão mudar suas regras para impedir a sobrepujança da competição sobre o lúdico (COLETIVO DE AUTORES, 1992, p.66).
\end{abstract}

Em ambas as turmas foi perceptível um grande avanço nas aulas, pois ao final das aulas os acadêmicos sempre perguntavamquem não havia conseguido fazer o pião girar com sucesso na aula anterior, e com o decorrer das atuações estes números foram sendo inferiores. Com tal conclusão, a acadêmica na última atuação com este conteúdo frisou novamente que quanto mais se praticar mais se conseguirá jogar com êxito.

No reinterpretar o insucesso e o erro para não fazer deles fontes de culpa ou castigo. Isso significa que se deve superar a perspectiva formal de entendimento da aprendizagem que a reduz a "erros e acertos". E necessário levar em conta que o erro compõe o processo de aprendizagem e faz parte da construção do domínio de novos conhecimentos, habilidades e atitudes (COLETIVO DE AUTORES, 1992, p.109).

Neste sentido, percebe-se também o princípio da provisoriedade do conhecimento, pois no inicio os mesmos não tinham o domínio do conhecimento e das técnicas, e com isso não conseguiam obter tanto resultado, mas no decorrer das aulas com a instrumentalização dos mesmos começou a haver um avanço no jogo.

Para finalização do conteúdo estava previsto no planejamento a realização de um circuito com todas as brincadeiras, para que os educandos pudessem rever as mesmas vistas durante o ano.Como forma de avaliação e registro foi planejada a realização de cartazes, entretanto o ano letivo estava em seu término, logo, tínhamos pouco tempo para finalizar o conteúdo. Portanto, em conversa junto ao grupo de bolsistas e a supervisora, decidiu-se por somente realizar a avaliação em cartaz, assim garantindo a avaliação, no qual suspeitávamosque havia sido de um caloroso resultado.

A partir disso, a acadêmica que ministrou essa aula, da confecção dos cartazes, a organizou didaticamente para que houvesse com maior sucesso, como Criar Educação, Criciúma, v. 6, n², julho/novembro 2017.- PPGE - UNESC 
por exemplo, a distribuição dos educandos em quatro grupos, em que estes deveriam elaborar um cartaz referente a uma das brincadeiras que thes foi conferida para elaborar. Dessa forma, os cartazes foram construídos e finalizados de maneira satisfatória, uma vez que os alunos conseguiram por meio dos cartazes expressar muitas das questões que se apropriaram nas aulas,assim sendofoi possível expressar o processo deensino e aprendizagem

Diante do exposto, também pensamos ser valido explicitar que tais atuações, não só com estas aulas, mas num geral de todo o ano letivo em que se desenvolveram atuações, observações e discussões, enfim todo o desenvolvimento do projeto, foi de grande contribuição na formação das acadêmicas. A experiência no programa trouxe a possibilidade das mesmas estarem vivenciando e se relacionando com o ambiente escolar numa dinâmica muitorica e semelhante ao que após sua formação irão encontrar na realidade escolar, pois proporcionou um convívio semanal com a escola, e não apenas algumas aulas ou dias isoladas. Neste sentido, fica nítida a importância da permanecia de tal política pública para a formação de futuros professores.

\section{CONSIDERAÇÕES FINAIS}

Mediante as atuações e discussões sobre a mesma, pudemos perceber que as turmas obtiveram um avanço significativo na apropriação do conhecimento, em que ao final de todos os conteúdos, ao ser realizado a avaliação, a grande maioria havia conseguido se apropriar da história e de algumas técnicas de jogo, sendo estes os objetivos do planejamento.

Diante disso, os mesmos elevaram suas funções psíquicas superiores, se apropriando do conhecimento sobre um determinado conteúdo que foi construído social e historicamente. Assim, é neste processo de apropriação do conteúdo que o ser humano se torna mais humano. "Esse processo ocorre pelo duplo movimento apropriação-objetivação da cultura: ao apropriar-se do que a humanidade já produziu culturalmente, o homem internaliza a cultura e se humaniza" (LONGAREZI; FRANCO, 2013, p.82).

Algo que também nos foi perceptível é com relação às brincadeiras, em que as mesmas apresentam aspectos e significados muito parecidos, uma vez que 
todas elas possuíam em sua gênese diversos significados, mostrando mais uma vez que o conhecimento é provisório.

Defende-se nesse trabalho uma organização do ensino por meio dos princípios de seleção e sistematização do conhecimento (COLETIVO DE AUTORES, 1992), assim como aqui relatado, visto que auxiliam no processo de apropriação dos conhecimentos por parte dos alunos. No decorrer do trabalho foi perceptível o resultado do trabalho pedagógico realizado com os educandos nessa referida escola, devido a análise dos cartazes confeccionados pelos mesmos, que permitiram verificar a apropriação de tais conhecimentos.

Além disso, por meio de atitudes dos alunos, como pedirem no intervalo jogos aprendidos nas aulas para brincarem, ao invés de jogos hegemônicos, percebe-se uma apropriação do conhecimento, possibilitando uma maior autonomia no momento de escolha de que brincadeira realizar no intervalo, pois tinham conhecimento de outras formas de brincar, e não apenas mais as formas hegemônicas.

Portanto, pensamos também que a experiência no projeto foi de grande contribuição na formação das acadêmicas, em que propiciou um contato direto com a realidade escolar, muito semelhante àquela em que as mesmas encontraram em sua vida profissional. Neste sentido, fica nítida a importância da permanecia de tal política pública para a formação de futuros professores.

\section{REFERÊNCIAS}

CAPES, PIBID-programa institucional de bolsa de iniciação a docência. Publicado em: 03 set, 2008. Disponível em: <http://www.capes.gov.br/educacaobasica/capespibid>. Acesso em: 03 fev. 2017.

\section{COLETIVO DE AUTORES, Metodologia do ensino de Educação Física. São} Paulo: Cortez, 1992.

KRUPPA. Sônia M. Portella. Sociologia da Educação. São Paulo, Cortez, 1994.

LEÓNTIEV, Alexis Nikolaevich. Actividad, conciencia e personalidade. Buenos Aires: Ed. cienciasdelhombre, 1978.

LIBÂNEO, José Carlos; FREITAS, Raquel A. Marra da Madeira. VasilyVasilyevichDavydov: a escola e a formação do pensamento teórico-científico.

Criar Educação, Criciúma, v. 6, n², julho/novembro 2017.- PPGE - UNESC 
In: LONGAREZI, Andréa Maturano; PUENTES, Roberto Valdés (Org.). Ensino desenvolvimental: vida, pensamento e obra dos principais representantes russos. Uberlândia: EDUFU, 2013. (Coleção biblioteca psicopedagógica e didática. Série ensino desenvolvimental; v. 1) p. 315-350.

LONGAREZI, Andréa Maturano; FRANCO, Patrícia Lopes. A.N Leontiev: A vida e obra do psicólogo da atividade. In: LONGAREZI, Andréa Maturano; PUENTES, Roberto Valdés (Org.). Ensino desenvolvimental: vida, pensamento e obra dos principais representantes russos. Uberlândia: EDUFU, 2013. (Coleção biblioteca psicopedagógica e didática. Série ensino desenvolvimental; v. 1) p. 67 -110.

SAVIANI, Demerval. Escola e democracia: teorias da educação, curvatura da vara, onze teses sobre educação e política $-7^{\mathrm{a}}$. Ed. São Paulo. Cortez, 1985

SILVANO, Sirléia; ORTIGARA Vidalcir. Currículo de formação ampliada e teoria da atividade de ensino na Educação Física escolar. RevistaPráxis Educativa, Ponta Grossa, v. 11, n. 2, p. 464-481, maio/ago. 2016 disponível em: <http://www.revistas2.uepg.br/index.php/praxiseducativa>

SOUZA, Herbert José. Como se faz análise de conjuntura. $3^{\circ}$ ed. Petrópolis. Vozes. 1984.

PONCE, Aníbal. Educação e Luta de Classes. $7^{\text {a }}$. Ed. São Paulo: Cortez, 1986. $195 \mathrm{p}$. 